\title{
Influence of anaemia in severely injured patients on mortality, transfusion and length of stay: An analysis of the TraumaRegister DGU®
}

\section{Linda Tanner}

Goethe-Universität Frankfurt am Main Fachbereich 16 Medizin: Goethe-Universitat Frankfurt am Main Fachbereich 16 Medizin

\section{Vanessa Neef}

Goethe-Universitat Frankfurt am Main Fachbereich 16 Medizin

\section{Florian Raimann}

Goethe-Universitat Frankfurt am Main Fachbereich 16 Medizin

\section{Philipp Störmann}

Goethe-Universitat Frankfurt am Main Fachbereich 16 Medizin

\section{Ingo Marzi}

Goethe-Universitat Frankfurt am Main Fachbereich 16 Medizin

\section{Rolf Lefering}

Witten/Herdecke University: Universitat Witten/Herdecke

\section{Kai Zacharowski}

Goethe-Universitat Frankfurt am Main Fachbereich 16 Medizin

Florian Piekarski ( $\nabla$ florian.piekarski@kgu.de)

Goethe-Universitat Frankfurt am Main Fachbereich 16 Medizin https://orcid.org/0000-0002-4095-3573

\section{Research Article}

Keywords: Anaemia, Polytrauma, Outcome, Mortality, Traumacenter, Transfusion, TraumaRegister DGU®

Posted Date: November 23rd, 2021

DOI: https://doi.org/10.21203/rs.3.rs-1104515/v1

License: (c) (i) This work is licensed under a Creative Commons Attribution 4.0 International License. Read Full License

Version of Record: A version of this preprint was published at European Journal of Trauma and Emergency Surgery on January 22nd, 2022. See the published version at https://doi.org/10.1007/s00068-021-01869-9. 


\section{Abstract \\ Purpose}

Anaemia is one of the leading causes of death among severely injured patients. Anaemia is known to increase the risk of death and prolong the length of hospital stay in various surgical groups. The main objective of this study is to analyse the anaemia rate on admission to the emergency department and the impact of anaemia on in-hospital mortality.

\section{Methods}

Data from the TraumaRegister DGU® (TR-DGU) between 2015 and 2019 was analysed. Inclusion criteria were age $>=16$ years and worst Abbreviated Injury Scale (AIS) score $\geq 3$. Patients were divided into three anaemia subgroups: no or mild anaemia (NA), moderate anaemia (MA) and severe anaemia (SA). Prehospital data, patient characteristics, treatment in the ER, outcomes, and differences between trauma centres were analysed.

\section{Results}

Of 67,595 patients analysed, $94.9 \%(n=64,153)$ exhibited no or mild anaemia $(\mathrm{Hb} \geq 9 \mathrm{~g} / \mathrm{dl}), 3.7 \%$ $(n=2,478)$ displayed moderate anaemia $(\mathrm{Hb} \mathrm{7-8} \mathrm{g} / \mathrm{dl})$ and $1.4 \%(n=964)$ presented with severe anaemia $(\mathrm{Hb}<7 \mathrm{~g} / \mathrm{dl})$. Haemoglobin $(\mathrm{Hb})$ values ranged from $3 \mathrm{~g} / \mathrm{dl}$ to $18 \mathrm{~g} / \mathrm{dl}$ with a mean $\mathrm{Hb}$ value of $12.7 \mathrm{~g} / \mathrm{dl}$. In surviving patients, anaemia was associated with prolonged length of stay (LOS). Multivariate logistic regression analyses revealed moderate $(p<0.001$ OR $1.88(1.66-2.13))$ and severe anaemia $(p<0.001$ OR 4.21 (3.46-5.12)) to be an independent predictor for mortality. Further significant predictors are ISS score per point (OR 1.0), age 70-79 (OR 4.8), age >80 (OR 12.0), severe pre-existing conditions (ASA 3/4) (OR 2.26), severe head injury (AIS 5/6) (OR 4.8), penetrating trauma (OR 1.8), unconsciousness (OR 4.8), shock (OR 2.2) and prehospital intubation (OR 1.6).

\section{Conclusion}

The majority of severely injured patients are admitted without anaemia to the ER. Injury-associated moderate and severe anaemia is an independent predictor of mortality in severely injured patients.

\section{Introduction}

Anaemia remains one of the leading causes of death in severely injured patients [1]. Anaemia can be both acute, caused by massive haemorrhage, and/or chronic at the time of admission [2]. Besides traumarelated coagulopathy, hypothermia, haemodilution and shock, anaemia therapy represents a key aspect in the treatment of severely injured patients. Furthermore, anaemia impacts patients' clinical outcomes and 
contributes to the costs associated with trauma [3]. Acute anaemia often requires the transfusion of red blood cells (RBCs) [4]. However, blood transfusions have shown to be an independent predictor for mortality, length of stay (LOS) in the intensive care unit (ICU) and systemic inflammatory response syndrome (SIRS) $[5,6]$.

The spectrum of patients, the outcome in trauma patients and the mechanism of trauma are diverse, ranging from common head and thoracic injuries to abdominal and pelvic injuries [7]. Patients with combined injuries or without head involvement tend to be younger than patients with isolated head injuries [7]. Elderly trauma patients more often present with lower haemoglobin $(\mathrm{Hb})$ levels in the emergency room (ER) and at discharge and more frequently receive transfusions of RBCs than do younger patients [8]. Furthermore, the severity of anaemia at admission predicted six-month mortality in geriatric patients [9]. Initial and lowest $\mathrm{Hb}$ after admission additionally predicted outcomes in patients with traumatic brain injuries [10]. Admission procedures take into account the particular importance of anaemia in severely injured patients via several prognostic scores, e.g. the 'revised injury severity classification' (RISC) II score [11].

This TraumaRegister DGU® (TR-DGU) study analyses the incidence of anaemia and effects of anaemia on in-hospital mortality as well as on red blood cell transfusion and length of hospital stay. Further possible factors influencing anaemia will be analysed.

\section{Materials And Methods}

The main objective of this study is to analyse the anaemia rate on admission to the emergency department and the impact of anaemia on in-hospital mortality. In addition, the study also investigates the transfusion rate and in-hospital outcomes of critically injured patients.

The TraumaRegister DGU ${ }^{\circledR}$ of the German Trauma Society (Deutsche Gesellschaft für Unfallchirurgie, DGU) was founded in 1993. The aim of this multi-centre database is the pseudonymised and standardised documentation of severely injured patients [12]. Participating hospitals are located in Germany (90\%), Belgium, Finland, Luxembourg, the Netherlands, Austria, Switzerland, Slovenia and the United Arab Emirates.

The register documents data from 1) the pre-hospital phase, 2) the ER, 3) ICU stays and 4) hospital discharge, including detailed information on patient demographics, the mechanism of trauma, comorbidities, pre- and in-hospital management, the course of treatment in the ICU, relevant laboratory findings, such as transfusion data, and final patient outcomes. Every patient whose ER admission results in death or a stay at the ICU of a participating trauma centre is included in the database.

The infrastructure for documentation, data management and data analysis are provided by the 'AUC Academy for Trauma Surgery', a company affiliated with the DGU. Scientific leadership is provided by the DGU's 'Committee on Emergency Medicine, Intensive Care and Trauma Management (Sektion NIS)'. Scientific data analysis is approved according to a peer review procedure outlined in the publication's 
guidelines for the TR-DGU. Approximately 30,000 cases from more than 650 hospitals are currently registered into the database annually.

Participation in the TR-DGU is voluntary. However, for hospitals associated with TraumaNetzwerk DGU ${ }^{\circledR}$, the entry of at least a basic data set is mandatory as part of the quality management programme.

The present study is in line with the publication guidelines of the TraumaRegister $\mathrm{DGU} \mathrm{U}^{\circledR}$ and registered under the TR-DGU project ID: 2020-054. The study was performed in accordance with the Declaration of Helsinki.

\section{Inclusion criteria}

Patients admitted to a German ER from 2015 to 2019 were analysed for this study. Inclusion criteria were age $>=16$ years and Abbreviated Injury Scale (AIS) score $\geq 3$. The Abbreviated Injury Scale (AIS) is an anatomically based injury severity rating system that classifies each injury by body region on a 6-point scale (AIS 1 - Minor up to AIS 6 - Maximum). Patients were classified into three categories of anaemia: 1) no or mild anaemia (NA; $\mathrm{Hb} \geq 9 \mathrm{~g} / \mathrm{dl}$ ), 2) moderate anaemia (MA; $\mathrm{Hb} 7-8 \mathrm{~g} / \mathrm{dl}$ ) and 3) severe anaemia $(\mathrm{SA} ; \mathrm{Hb}<7 \mathrm{~g} / \mathrm{dl})$. The registry does not collect any chronic anaemia parameters; therefore, patients with low $\mathrm{Hb}$ values $(\mathrm{Hb}<9 \mathrm{~g} / \mathrm{dl})$ but normal blood pressure $(>110 \mathrm{mmHg})$ and only minor pre-hospital volume therapy $(<1000 \mathrm{~mL})$ were defined as chronically anaemic. Transfusion rate was defined as a minimum of 1 transfusion of an RBC-unit per patient in relation to the total number of patients in the ER.

Patients who were transferred during treatment were excluded because of missing data from the prehospital phase (transfer in cases) or missing hospital outcome (transfer out cases), respectively.To facilitate comparisons, patients with missing values for $\mathrm{Hb}(2.1 \%)$ or prehospital volume therapy (9.2\%) were also excluded.

\section{Statistical analysis}

Anaemia at admission to the ER, transfusion of RBCs, volume therapy, anticoagulation, mechanism of trauma, ICU stay, cause of death, pre-hospital time of rescue, and general fatality were analysed. Possible factors influencing anaemia are evaluated descriptively. These include prehospital volume therapy, haemodynaemic situation, intake of anticoagulation, injury severity and injury pattern. In the register, the following drugs are recorded as anticoagulants: Acetylsalicylacid (ASS), vitamin K antagonists, new oral anticoagulants (NOACs) and heparin.

Multivariable logistic regression analysis was performed with hospital mortality as dependent variable. The variables were adapted from the RISC-2 score. Besides anaemia, the following variables were included as potential predictors (independent variables): age, sex, pre-injury disease, injury severity score, head injury, penetrating trauma, unconsciousness, shock, prehospital intubation and volume therapy, and hospital level of care. 
The predictability of mortality on the basis of the RISC-2 score, a 13-factor prognostic score for mortality, as a function of the severity of anaemia will be assessed in a multivariate model.

Statistical analysis was performed using SPSS Statistics (Version 24, IBM, Armonk, New York). Descriptive results are presented as counts and percentages for categorical data, and as mean with standard deviation (SD) or as median with inter-quartile range (IQR) for metric data, respectively. Resulting odds ratios are presented with $95 \%$ confidence intervals $(\mathrm{Cl})$. A p value below 0.05 was considered significant. Illustrations were created with Prism (Version 9.1.0 for macOS, GraphPad Software, SanDiego).

\section{Results}

A total of 67,595 severely injured patients (AIS $\geq 3$ ) were analysed between 2015 to 2019 . The demographic data and mechanism of trauma are shown in Table 1. 
Table 1

Demographics, anaemia, transfusion, outcomes and mechanism of trauma.

\begin{tabular}{|c|c|c|c|c|}
\hline & & $\begin{array}{l}\text { No or mild } \\
\text { anaemia (NA) }\end{array}$ & $\begin{array}{l}\text { Moderate } \\
\text { anaemia (MA) }\end{array}$ & $\begin{array}{l}\text { Severe } \\
\text { anaemia }\end{array}$ \\
\hline & & 64153 & 2478 & \\
\hline & & [n (\%)] & [n (\%)] & [n (\%)] \\
\hline Demographics & Female & $18631(92.4 \%)$ & $1103(5,4 \%)$ & $424(2.1 \%)$ \\
\hline & Male & $45522(96.0 \%)$ & $1375(2.9 \%)$ & $540(1.1 \%)$ \\
\hline & $<60$ years & $36168(95.8 \%)$ & $1100(2.9 \%)$ & $493(1.3 \%)$ \\
\hline & $\geq 60$ years & $27985(93.8 \%)$ & $1378(4.6 \%)$ & $471(1.6 \%)$ \\
\hline & ASA >3 12641 & $11580(91.6 \%)$ & $785(6.2 \%)$ & $276(2.2 \%)$ \\
\hline & ISS & $19.9 \pm 10.3$ & $28.9 \pm 16.0$ & $33.6 \pm 17.9$ \\
\hline Anaemia and & Acute anaemia & Not applicable & $1742(69.1 \%)$ & $780(30.9 \%)$ \\
\hline & Chronic anaemia & Not applicable & $666(80.9 \%)$ & $157(19.1 \%)$ \\
\hline & $\mathrm{Hb} \mathrm{g} / \mathrm{dl}$ mean & $13.4 \pm 1.8$ & $8.1 \pm 0.6$ & $5.8 \pm 1.0$ \\
\hline & $\mathrm{RBC}$ transfusion in ER & $3710(70.2 \%)$ & $971(18.4 \%)$ & $604(11.4 \%)$ \\
\hline & $>10$ RBC Units in ER & $377(55.0 \%)$ & $178(26.0 \%)$ & $130(19.0 \%)$ \\
\hline & RBC Units in ER & $0.27 \pm 1.7$ & $2.5 \pm 5.5$ & $4.8 \pm 8.2$ \\
\hline & $\begin{array}{l}\text { Trauma-associated severe } \\
\text { haemorrhage score }\end{array}$ & $3.9 \pm 3.4$ & $12.8 \pm 4.4$ & $16.6 \pm 4.7$ \\
\hline & Fresh frozen plasma in ER & $2180(72.4 \%)$ & $513(17.0 \%)$ & $320(10.6 \%)$ \\
\hline & Thrombocytes in ER & $527(63.6 \%)$ & $182(22.0 \%)$ & $119(14.4 \%)$ \\
\hline & $P C C$ in ER & 1295 (73.5\%) & $297(16.9 \%)$ & 169 (9.6\%) \\
\hline & Fibrinogen in ER & 5105 (84.0\%) & $651(10.7 \%)$ & $324(5.3 \%)$ \\
\hline & Tranexamic acid PH & $4617(87.1 \%)$ & $446(8.4 \%)$ & $238(4.5 \%)$ \\
\hline & Volume therapy $\mathrm{PH}(\mathrm{ml})$ & $695 \pm 526$ & $1098 \pm 854$ & $1386 \pm 1107$ \\
\hline & Volume therapy ER (ml) & $1113 \pm 1435$ & $1975 \pm 2288$ & $2528 \pm 2660$ \\
\hline Anticoagulation & ASS & $6100(94.2 \%)$ & $288(4.4 \%)$ & $86(1.3 \%)$ \\
\hline
\end{tabular}

The percentage in each group (SA, MA, NA) is given in brackets (\%). The total $n$ per item may differ because individual items are documented with different frequency.

${ }^{1}$ Combined head injury $=$ Head injury and $\geq 1$ other injury pattern (e.g. abdominal or thoracic trauma) 


\begin{tabular}{|c|c|c|c|c|}
\hline & & $\begin{array}{l}\text { No or mild } \\
\text { anaemia (NA) }\end{array}$ & $\begin{array}{l}\text { Moderate } \\
\text { anaemia (MA) }\end{array}$ & $\begin{array}{l}\text { Severe } \\
\text { anaemia } \\
\text { (SA) }\end{array}$ \\
\hline & & 64153 & 2478 & \\
\hline & & {$[n(\%)]$} & {$[n(\%)]$} & 904 \\
\hline & & & & [n (\%)] \\
\hline & Direct oral anticoagulants & $2224(92.0 \%)$ & $147(6.1 \%)$ & $47(1.9 \%)$ \\
\hline & Vitamin $\mathrm{K}$ antagonists & $2365(92.8 \%)$ & $131(5.1 \%)$ & $52(2.0 \%)$ \\
\hline Haemodynamics & $\begin{array}{l}\text { Shock (syst. BP } \leq \\
90 \mathrm{mmHg} \text { ) in ER }\end{array}$ & $4330(80.8 \%)$ & $675(12.6 \%)$ & $354(6.6 \%)$ \\
\hline & RR Syst (mmHG) PH & $136.5 \pm 32.1$ & $113.3 b \pm 42.2$ & $98.2 \pm 47.0$ \\
\hline & RR Syst $(\mathrm{mmHG})$ in ER & $136.1 \pm 29.5$ & $110.6 \pm 39.1$ & $94.1 \pm 44.3$ \\
\hline & Vasopressors in ER & $4750(83.0 \%)$ & $632(11.0)$ & $344(6.0 \%)$ \\
\hline & CPR in ER & $459(62.4 \%)$ & $135(18.4 \%)$ & $141(19.2 \%)$ \\
\hline Outcome & Mortality & $7181(83.3 \%)$ & $910(10.6 \%)$ & $533(6.2 \%)$ \\
\hline & RISC II Score & $10.2 \%$ & $34.0 \%$ & $55.3 \%$ \\
\hline & Dead in ER & $471(58.0 \%)$ & $178(21.9 \%)$ & $163(20.1 \%)$ \\
\hline & Dead in $24 \mathrm{~h}$ & 3191 (76.9\%) & $570(13.7 \%)$ & $393(9.5 \%)$ \\
\hline & Stay on ICU (days) & $6.2 \pm 9.9$ & $10.6 \pm 16.3$ & $9.0 \pm 24.6$ \\
\hline & Lengh of in-hospital stay & $16.0 \pm 16.2$ & $19.8 \pm 24.4$ & $16.6 \pm 24.6$ \\
\hline & Multiorgandysfunction & $5429(87.8 \%)$ & $517(8.4 \%)$ & $238(3.8 \%)$ \\
\hline & Sepsis & $1721(89.2 \%)$ & $140(7.3 \%)$ & $69(3.6 \%)$ \\
\hline Mechanism and & Head injury & $9706(96.3 \%)$ & $297(2.9 \%)$ & $80(0.8 \%)$ \\
\hline & Combined head injury ${ }^{1}$ & $22518(93.5 \%)$ & $1117(4.6 \%)$ & $460(1.9 \%)$ \\
\hline & GCS $<8$ & $9943(87.8 \%)$ & $904(8.0 \%)$ & $480(4.2 \%)$ \\
\hline & Thorax (AIS >=3) & $31484(94.3 \%)$ & $1344(4.0 \%)$ & $558(1.7 \%)$ \\
\hline & Abdomen (AIS >=3) & $6905(89.3 \%)$ & $523(6.8 \%)$ & $306(4.0 \%)$ \\
\hline & Extremities (AIS >=3) & 18606 (91.9\%) & $1143(5.6 \%)$ & $493(2.4 \%)$ \\
\hline & Traffic accident by car & $12945(95.0 \%)$ & $476(3.5 \%)$ & $201(1.5 \%)$ \\
\hline
\end{tabular}

The percentage in each group (SA, MA, NA) is given in brackets (\%). The total $n$ per item may differ because individual items are documented with different frequency.

${ }^{1}$ Combined head injury $=$ Head injury and $\geq 1$ other injury pattern (e.g. abdominal or thoracic trauma) 


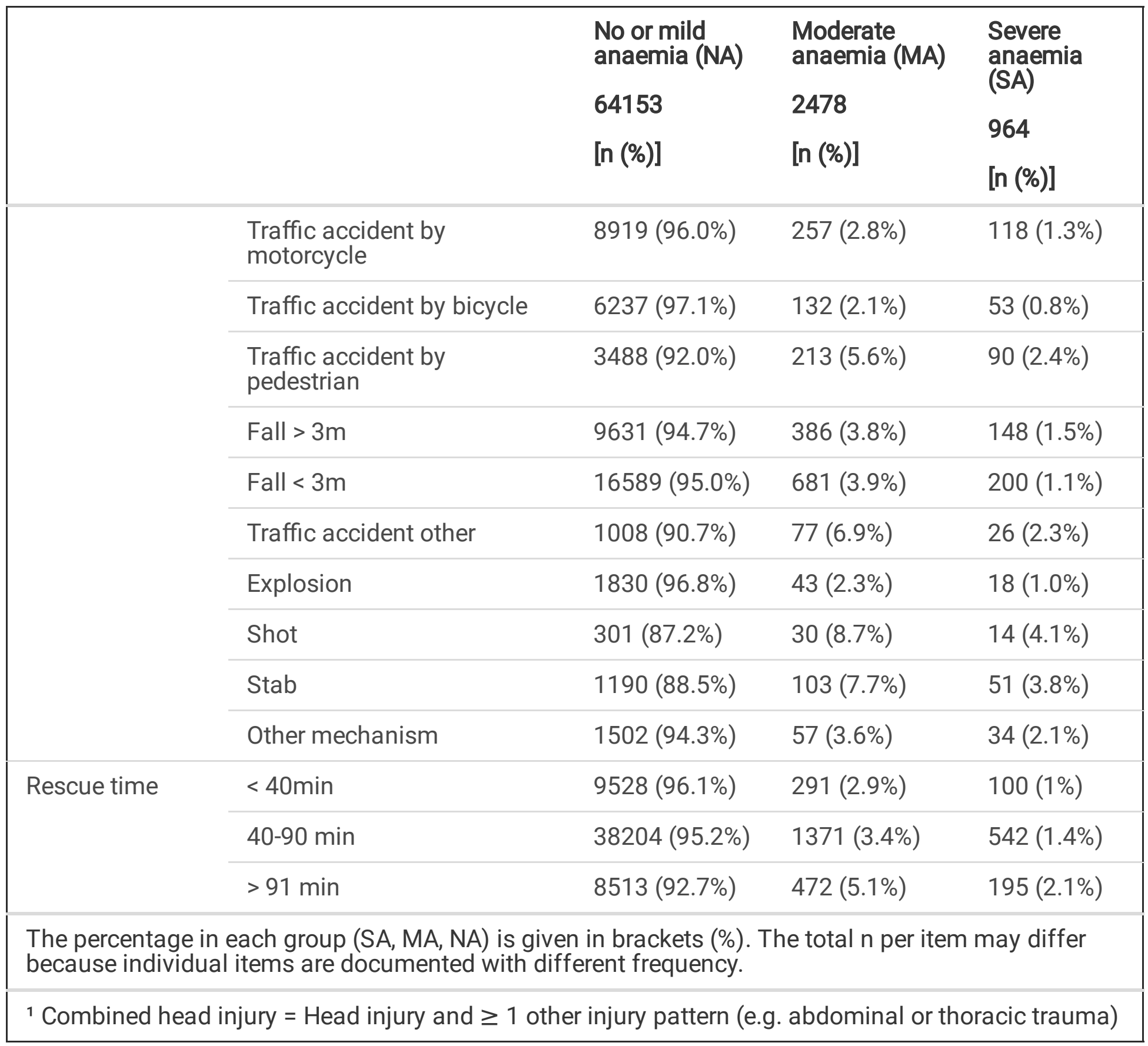

The mean ISS was $19.9 \pm 10.3$ in the non-anaemic, $28.9 \pm 16.0$ in the moderately anaemic and $33.6 \pm 17.9$ in the severely anaemic group. Trauma-related major bleeding score was higher with increasing anaemia level (NA: $3.9 \pm 3.4$, MA: $12.8 \pm 4.4$, SA: $16.6 \pm 4.7$ ).

\section{Anaemia and transfusion}

Among the severely injured patients in the study, 64,153 (94.9\%) had no or mild anaemia $(\mathrm{Hb} \geq 9 \mathrm{~g} / \mathrm{dl})$, 2,478 (3.7\%) presented with moderate anaemia $(\mathrm{Hb} 7-8 \mathrm{~g} / \mathrm{dl})$ and $964(1.4 \%)$ patients exhibited severe anaemia $(\mathrm{Hb}<7 \mathrm{~g} / \mathrm{dl})$. Haemoglobin values ranged from 3-18 g/dl with a mean $\mathrm{Hb}$ value of $13.1 \pm 2.2$ g/dl (Fig. 2a). Among all patients, 823 (1.2\%) had chronic anaemia, and 2,522 had acute anaemia (3.7\%). 
In total, 7.8\% (5285) of patients were transfused. Severe anemia is associated with a higher transfusion rate $(65.4 \%)$ than MA $(40.0 \%)$ and NA (5.8\%). Among female patients, the proportion of MA was higher $(5.5 \%)$ than among male patients (2.9\%), likewise the proportion of SA was higher $(2.1 \%)$ than among male patients (1.1\%). The highest rates of MA and SA are found in shooting injuries (MA 8.7\%, SA 4.1\%), stabbing injuries (MA 7.7\%, SA 3.8\%), and traffic accidents by pedestrian (MA 5.6\%, SA 2.4\%) (Table 1).

Massive transfusions of more than 10 red cell units per patient were recorded in the context of severe anaemia at $14.1 \%$ percent, compared to $0.6 \%$ for NA and $7.3 \%$ for MA. RBC transfusion rate in ER increases with lower $\mathrm{Hb}$ values reaching a maximum in patients with $\mathrm{Hb}$ values of $4 \mathrm{~g} / \mathrm{dl}$ and a minimum in patients with $\mathrm{Hb}$ values of $15-17 \mathrm{~g} / \mathrm{dl}$ (Fig. $2 \mathrm{C}$ ). Analysis showed that patients with severe anaemia $(42.3 \%)$ were more likely to suffer from haemodynamic instability, defined by a systolic blood pressure below $90 \mathrm{mmHG}$, than patients with no (7.1\%) or moderate anaemia $30.0 \%)$. Patients with severe anaemia received on a mean basis more fluid therapy in the prehospital and shock room phase compared to the other groups (Table 1). Pre-hospital values for volume therapy ranged from $500 \mathrm{~mL}$ for patients with high $\mathrm{Hb}$ values to a maximum of $1500 \mathrm{~mL}$ for patients with $\mathrm{Hb}$ values $<5 \mathrm{~g} / \mathrm{dl}$ (Fig. 2B).

\section{Outcome}

Multivariate logistic regression analyses revealed moderate ( $p<0.01$ OR 1.88 (1.66-2.13) and severe anaemia ( $p<0.01$ OR 4.21 (3.46-5.12) to be an independent risk factor for higher mortality (Table 2). Thus, mortality rate increases with severity of anaemia, ranging from $4.7 \%$ in NA patients to $72.1 \%$ in SA patients (Fig. 2D). Patients with SA died most often in the ER (17.0\%) and within 24 hours after admission to ER (23.0\%), while patients with MA most often died within 24 hours after admission to ER (15.6\%). Multivariable logistic regression analyses revealed that age, pre-existing diseases, ISS score per point, severity of head injury (AIS $>4$ ), shock, unconsciousness, and anaemia are predictors for higher mortality (Table 2). The group with moderate anaemia has the longest mean length of stay in hospital (19.8 \pm 24.4 days) and the longest length of stay in intensive care (10.6 \pm 16.4 days). Shorter lengths of stay are seen in severe anaemia (ICU: $9.0 \pm 15.1$ and LOS: $17.6 \pm 24.6$ and without anaemia (ICU: 16.0 \pm 16.2 and LOS: $6.2 \pm 9.9$ days) (Figure 3 ). 
Table 2

Multivariate analysis of independent predictors for mortality

\begin{tabular}{|lllll|}
\hline Predictor & Value & p-value & Odds Ratio & 95\% Cl for OR \\
\hline Age (years) & $60-69$ & $<.001$ & 2.33 & $2.09-2.60$ \\
(reference Age: 16-59 years) & $70-79$ & $<.001$ & 4.84 & $4.38-5.34$ \\
& $80+$ & $<.001$ & 12.04 & $10.89-13.30$ \\
\hline Sex & males & .007 & 1.10 & $1.03-1.18$ \\
\hline Preexisting diseases & ASA 3/4 & $<.001$ & 2.26 & $2.09-2.43$ \\
\hline Injury Severity Score & per point & $<.001$ & 1.041 & $1.038-1.044$ \\
\hline Head injury severity & AIS 3 & .632 & 0.98 & $0.88-1.08$ \\
(reference: AIS 0-2) & AlS 4 & $<.001$ & 1,29 & $1.17-1.42$ \\
\hline Penetrating trauma & AlS 5/6 & $<.001$ & 4.76 & $4.32-5.23$ \\
\hline Unconscious (GCS 3-8) & yes & $<.001$ & 1.80 & $1.52-2.15$ \\
\hline Shock (syst. BP $\leq 90 \mathrm{mmHg})$ & yes & $<.001$ & 4.83 & $4.40-5.31$ \\
\hline Prehospital intubation & yes & $<.001$ & 2.19 & $2.01-2.38$ \\
\hline Prehospital volume therapy & $\geq 1000$ ml & .149 & 0.93 & $0.84-1.03$ \\
\hline Level of care & Level 2 & .033 & 1.09 & $1.01-1.17$ \\
(reference: Level 1) & Level 3 & .253 & 0.92 & $0.80-1.06$ \\
\hline Anaemia & moderate anaemia & $<.001$ & 1.88 & $1.66-2.13$ \\
(reference: no or mild anaemia) & severe anaemia & $<.001$ & 4.21 & $3.46-5.12$ \\
\hline
\end{tabular}

RISC II scores offer an adequate prognosis of death in patients with NA and SA but fail to predict death in patients with MA. A multivariable analysis reveals that the same results can be applied to the three levels of trauma centres (Level I-III centres). RISC II scores modelled mortality equally well for each trauma centre. Across levels, the outcomes for NA and SA patients were well estimated by RISC II scores.

\section{Discussion}

In this study, we revealed that in-hospital mortality and transfusion rates increased with the severity of anaemia and that anaemia was associated with prolonged Hospital-LOS [13]. Multivariable analyses revealed that severe and moderate anaemia are a risk factor for higher mortality. 
Among trauma patients, anaemia remains one of the most common causes of death upon admission to the ER [1]. Massive haemorrhage due to severe trauma can cause acute anaemia. Severe anaemia in trauma patients is a consequence of a sustained severe injury, yet there was a higher OR for severe anaemia (OR 4.21) compared to other predictors such as shock, defined as syst $B P \leq 90 \mathrm{mmHg}$, (OR 2.19), penetrating trauma (OR 1.80). SA had a similar OR to severe head injury (AIS 5/6: OR 4.76), age over 70 years (OR 4.84-12.04) or unconsciousness at the scene (OR 4.83). These results are in line with the findings of Lefering et al. who also showed a significant influence $(p<0.001$ OR: 1.45$)$ of traumatic anaemia on mortality with a haemoglobin limit value of less than $12 \mathrm{~g} / \mathrm{dl}$ [11]. Froessler et al. revealed that anaemia increases mortality, LOS and costs associated with trauma management [3].

In the emergency setting, treatment usually involves RBC transfusions. RBC transfusions, in turn, are associated with greater mortality, an increased risk for SIRS and prolonged ICU and hospital stays $[5,6]$.

In summary, 67,595 injured patients were analysed. Both the mean $\mathrm{Hb}$ values and the distribution of $\mathrm{Hb}$ values from trauma patients are comparable to the German population in general [14]. Although this study included only severely injured patients with AIS scores $\geq 3$, the majority of patients were admitted without anaemia to the ER. Pre-clinically applied volume resuscitation has an influence on patients' $\mathrm{Hb}$ concentrations at the time of ER admission [15]. Pre-hospital mean volume resuscitation ranged from $500 \mathrm{~mL}$ for patients with high $\mathrm{Hb}$ values to a maximum of $1.5 \mathrm{~L}$ for patients with $\mathrm{Hb}$ values $<5 \mathrm{~g} / \mathrm{dl}$. These findings align with the current guidelines for pre-hospital trauma management [16]. According to data from the TraumaRegister DGU®, volume resuscitation has become more restrictive during the last decade [15]. Our analysis demonstrated that patients with SA received a maximum of $1500 \mathrm{~mL}$ crystalloid volume, minimising the risk for haemodilution and coagulopathy. Thus, it can be assumed that the determined $\mathrm{Hb}$ values used for this analysis are both realistic and caused by haemorrhage and not by haemodilution.

The RBC transfusion rate in anaemic patients increased exponentially with decreasing $\mathrm{Hb}$ values. Patients with an $\mathrm{Hb}$ value of $8 \mathrm{~g} / \mathrm{dl}$ showed signs of chronic anaemia in $40 \%$ of all registered cases, a finding that reflects the current prevalence of chronic anaemia in adults. Chronic anaemia is present in $17 \%$ of adults over 60 years and in $40 \%$ of elderly patients [17]. Because anaemia is associated with functional restrictions, limited mobility and decreased stability and balance, moreover, it also increases the risk for falls [18]. Laboratory values that are indicative of chronic anaemia, such as transferrin saturation, are not collected in the registry. Therefore, prospective studies are needed to further investigate the influence of chronic anaemia in trauma patients.

We found that anticoagulation in severely injured patients seemed not to be associated with anaemia. Compared to anaemic trauma patients, all trauma patients in our analysis had a similar distribution of anticoagulant medication. Neither of the different anticoagulation groups was associated with a greater risk for anaemia at admission. This result is surprising since the use of antiplatelet medications or anticoagulation is associated with an increased bleeding tendency and coagulopathy. It also increases the importance of point-of-care coagulation testing (POCT) in the ER. Based on the available data in this 
analysis, it shows that in severely injured patients with severe anaemia, POCT diagnostics were performed in $12.4 \%$ of cases. ASS impacts thrombocyte function, which can be rapidly diagnosed with viscoelastic measurements in the ER or during surgery [19]. Point-of-care analyses, such as viscoelastic measurements, platelet function tests or blood gas analysis, can enable the rapid detection of massive bleeding and, due to their quicker results and the smaller sample sizes required, should be favoured to laboratory testing. With a rapid turnaround time and minimal sample size, blood gas analysis has proven to be a valid measurement method for Hb values in the ER [20]. POCT must be part of patients' blood management, ultimately improving the patient outcomes [21]. Due to the lack of haemodilution, results from this testing can be safely used for clinical decision-making.

Several studies have already demonstrated the increased mortality of anaemic patients [1]. Our study has reproduced these results for a cohort of severely injured patients. In our study, however, patients with SA tended to die rather quickly -in the ER or during the first 24 hours after injury, while patients with MA more often survived the acute phase in the ER but died during emergency surgery or within 24 hours of admission to the ICU. In our analysis, $40.6 \%$ of the presumed causes of death of patients with severe anaemia were documented as traumatic brain injury, $31.2 \%$ as haemorrhage or organ failure with $20.5 \%$ and $7.7 \%$ as other causes. The massive haemorrhage can be specifically addressed and leads to several complications such as organ malperfusion or coagulopathy [22]. Trauma centres have established protocols for mass transfusions to ensure fast and correct decisions during haemorrhage. Survivors spent almost half of their hospital stays on ICU while non-survivors tended to die in the ICU. LOS was prolonged by the presence of moderate anaemia. In the case of severe anaemia, the LOS decreased again, but was still considerably longer than in patients without anaemia. Thus, our findings are consistent with study results from other clinical settings where the presence of anaemia has been identified as an independent prognostic factor [23]. They also underscore the need for early detection of anaemia and initiation of immediate therapy.

The RISC II score was established as a prognosis marker for mortality in severely injured patients. It contains 13 variables: worst and second-worst injury (AIS severity level), head injury, age, sex, pupil reactivity and size, pre-injury health status, blood pressure, acidosis (base deficit), coagulation, haemoglobin and cardiopulmonary resuscitation [11]. In a multivariable analysis, we compared RISC II scores for severely injured patients with registered data from the TraumaRegister DGU $\AA$ associated with different levels of trauma centres (supraregional, regional and local). RISC II scores predicted mortality equally well across all three trauma centres and for patients with NA and SA. However, patients with MA exhibited minor deviations from their RISC II prognoses, which might be caused by the misinterpretation of low $\mathrm{Hb}$ values as acute anaemia rather than chronic anaemia. Indeed, RISC II scores predicted lower mortality in patients with MA than those found in our analysis, and the prevalence of chronic anaemia as a pre-existing condition can complicate recovery from trauma and thus increase mortality [10]. Our study also did not observe the higher mortality rates, predicted by RISC II scores, for Level II and III centres compared to Level I centres. These results differ from the findings of Hilbert et al. from 2010. Dividing trauma centres into groups according to mortality rates, which they calculated using RISC II scores, they found that mortality rates at the lowest 10 centres were twice as high as those at the top 10 centres [24]. 
Their analysis, however, utilised data from 2004 to 2007, while we analysed data from 2015 to 2019. Presumably, trauma centres have developed over the last decade. In particular, the implementation of the TraumaRegister DGU® improved outcomes at smaller trauma centres by comparing and analysing treatment of severely injured patients. While, in their 2010 study, Hilbert et al. found an impact for prehospital time, time management, diagnostic approach and fluid resuscitation on patient outcomes, our analysis employed the modified RISC II score, which included neither trauma level nor any of the factors mentioned above. Thus, we can assume that the improved outcomes of patients treated at Level II and III trauma centres were not influenced by external factors but by the subsequently updated standards of care under Level 3 guidelines for the treatment of patients with severe/multiple injuries [25].

\section{Limitations}

This is a retrospective analysis of the TraumaRegister DGU®. Because registered data is less valid than data taken from a prospective randomised study, the results we observed should be seen only as associations and not as causations. Finally, because the database we employed is generated by medical personnel, it is vulnerable to human bias.

\section{Conclusions}

The majority of severely injured patients are admitted without anaemia to the ER. Injury-associated moderate and severe anaemia is an independent predictor of mortality in severely injured patients.

\section{Declarations}

\section{Statements and Declarations}

$\mathrm{RL}$ declares that his institution (University Witten/Herdecke) receives an ongoing support from AUC Akademie der Unfallchirurgie $\mathrm{GmbH}$, the dataholder of the TR-DGU, which includes statistical support in data analysis. There are no conflicts of interest associated with this article. All other authors declare that there are no conflicts of interest with regard to the article.

\section{Funding}

No funding has been received in connection to this study.

\section{Abbreviations}

AIS Abbreviated Injury Scale

AUC AUC - Akademie der Unfallchirurgie GmbH

ASA American Society of Anesthesiologists Physical Status Score 


\begin{tabular}{|c|c|}
\hline ASS & Acetylsalicylacid \\
\hline CPR & Cardiopulmonary resuscitation \\
\hline DGU & Deutsche Gesellschaft für Unfallchirurgie e.V \\
\hline ER & Emergency room \\
\hline GCS & Glasgow Coma Scale \\
\hline $\mathrm{Hb}$ & Haemoglobin \\
\hline ICU & Intensive Care Unit \\
\hline ISS & Injury Severity Score \\
\hline LOS & Length of hospital stay \\
\hline MA & moderate anaemia \\
\hline NA & no or mild anaemia \\
\hline NOAC & new oral anticoagulants \\
\hline PCC & Prothrombin complex concentrate \\
\hline $\mathrm{PH}$ & Prehospital \\
\hline $\mathrm{RBC}$ & red blood cell \\
\hline RISC-2 & Revised Injury Severity Classification II \\
\hline SA & severe anaemia \\
\hline SIRS & systemic inflammatory response syndrome \\
\hline TR-DGU & TraumaRegister DGU ${ }^{\circledR}$ \\
\hline
\end{tabular}

\section{References}

1.Spahn, D.R., et al., The European guideline on management of major bleeding and coagulopathy following trauma: fifth edition. Critical Care, 2019. 23(1): p. 98.

2.Rosenthal, C., von Heymann, C., Kaufner, L., Diagnostik und Behandlung der präoperativen Anämie. Der Anaesthesist, 2019. 68(8): p. 555-567. 
3.Froessler, B., Kurmis, A., Papendorf, D., Is there an indication to utilize intravenous iron in acute trauma patients? Why, how, and when. Curr Opin Anaesthesiol, 2020. 33(2): p. 227-233.

4.Gando, S., Hayakawa, M., Pathophysiology of Trauma-Induced Coagulopathy and Management of Critical Bleeding Requiring Massive Transfusion. Semin Thromb Hemost, 2016. 42(2): p. 155-65.

5.Dunne, J.R., et al., Blood transfusion is associated with infection and increased resource utilization in combat casualties. Am Surg, 2006. 72(7): p. 619-25; discussion 625-6.

6.Dunne, J.R., et al., Allogenic blood transfusion in the first 24 hours after trauma is associated with increased systemic inflammatory response syndrome (SIRS) and death. Surg Infect (Larchmt), 2004. 5(4): p. 395-404.

7. Jahresbericht 2020 des TraumaRegister DGU®. 2020. 8.Loftus, T.J., et al., Anemia and blood transfusion in elderly trauma patients. J Surg Res, 2018. 229: p. 288-293.

9.Ong, A.W., et al., Anemia at Discharge in Elderly Trauma Patients Is Not Associated with Six-Month Mortality. Am Surg, 2019. 85(7): p. 708-711.

10.Litofsky, N.S., et al., The Negative Impact of Anemia in Outcome from Traumatic Brain Injury. World Neurosurg, 2016. 90: p. 82-90.

11.Lefering, R., et al., Update of the trauma risk adjustment model of the TraumaRegister DGU: the Revised Injury Severity Classification, version II. Crit Care, 2014. 18(5): p. 476.

12.Ruchholtz, S., et al., [The trauma register of the 'Polytrauma' Committee of the German Society of Trauma Surgery as the basis for quality management in the management of severely injured patients]. Langenbecks Arch Chir Suppl Kongressbd, 1997. 114: p. 1265-7.

13.Loor, G., et al., The least of 3 evils: exposure to red blood cell transfusion, anemia, or both? J Thorac Cardiovasc Surg, 2013. 146(6): p. 1480-1487 e6.

14. World Health Organization, Haemoglobin concentrations for the diagnosis of anaemia and assessment of severity. Vitamin and Mineral Nutrition Information System. Geneva, World Health Organization, 2011. WHO/NMH/NHD/MNM/11.1.

15.Driessen, A., et al., Prehospital volume resuscitation-Did evidence defeat the crystalloid dogma? An analysis of the TraumaRegister DGU(R) 2002-2012. Scand J Trauma Resusc Emerg Med, 2016. 24: p. 42.

16.Unfallchirurgie, D.G.f.r., S3-Leitlinie Polytrauma / Schwerverletzten-Behandlung. 2016.

17.Lanier, J.B., Park, J. J., Callahan, R. C., Anemia in Older Adults. Am Fam Physician, 2018. 98(7): p. 437442. 
18.Penninx, B.W., et al., Anemia and decline in physical performance among older persons. Am J Med, 2003. 115(2): p. 104-10.

19.Holcomb, J.B., et al., Admission rapid thrombelastography can replace conventional coagulation tests in the emergency department: experience with 1974 consecutive trauma patients. Ann Surg, 2012. 256(3): p. 476-86.

20.Tanner, L., et al., Factors influencing the bias between blood gas analysis versus central laboratory hemoglobin testing. A secondary analysis of a randomized controlled trial. PLoS One, 2020. 15(10): p. e0240721.

21.Meybohm, P., et al., Patient Blood Management is Associated With a Substantial Reduction of Red Blood Cell Utilization and Safe for Patient's Outcome: A Prospective, Multicenter Cohort Study With a Noninferiority Design. Ann Surg, 2016. 264(2): p. 203-11.

22.Lee, C.C., et al., A current concept of trauma-induced multiorgan failure. Ann Emerg Med, 2001. 38(2): p. 170-6.

23.Bross, M.H., Soch, K., Smith-Knuppel, T., Anemia in older persons. Am Fam Physician, 2010. 82(5): p. 480-7.

24. Hilbert, P., Lefering, R., Stuttmann, R., Trauma care in Germany: major differences in case fatality rates between centers. Dtsch Arztebl Int, 2010. 107(26): p. 463-9.

25. Polytrauma Guideline Update, Group, Level 3 guideline on the treatment of patients with severe/multiple injuries: AWMF R

\section{Figures}




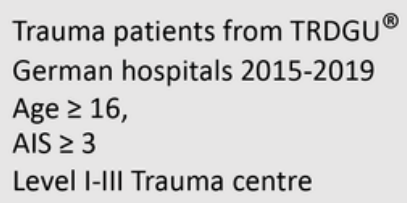

Level I-III Trauma centre

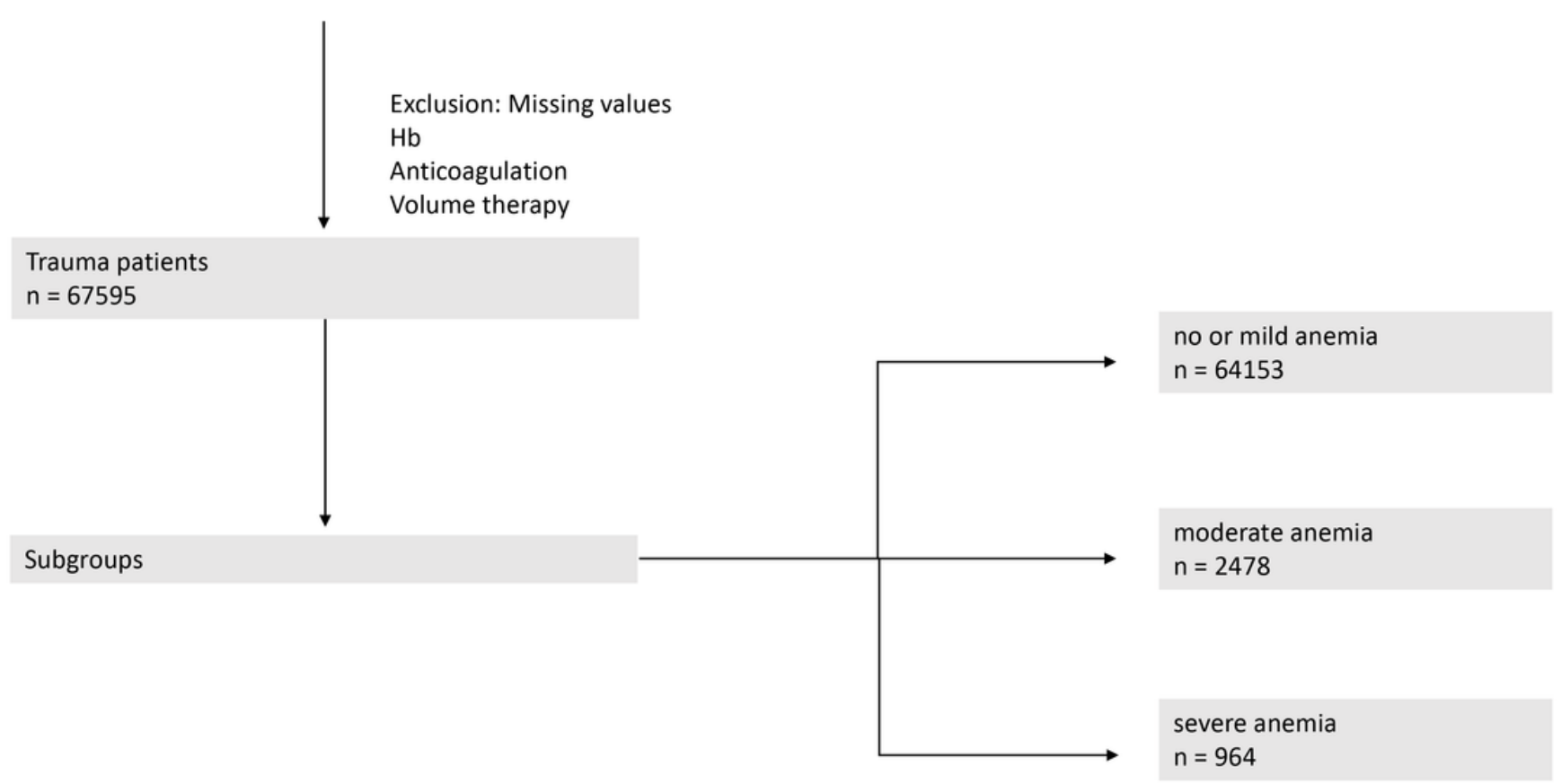

\section{Figure 1}

Flow chart for patient inclusion. Patients (aged $\geq 16$ years) for primary analysis were included with an Abbreviated Injury Scale (AIS) of $\geq 3$ who were directly admitted to a German trauma centre (TraumaZentrum DGU®) from 2015 to 2019. Patients were divided into anaemia subgroups (no or mild anaemia $\mathrm{Hb} \geq 9 \mathrm{~g} / \mathrm{dl}$, moderate anaemia $\mathrm{Hb} 7-8 \mathrm{~g} / \mathrm{dl}$, severe anaemia $\mathrm{Hb}<7 \mathrm{~g} / \mathrm{dl}$ ). AlS = Abbreviated Injury Scale, $\mathrm{Hb}=$ haemoglobin 

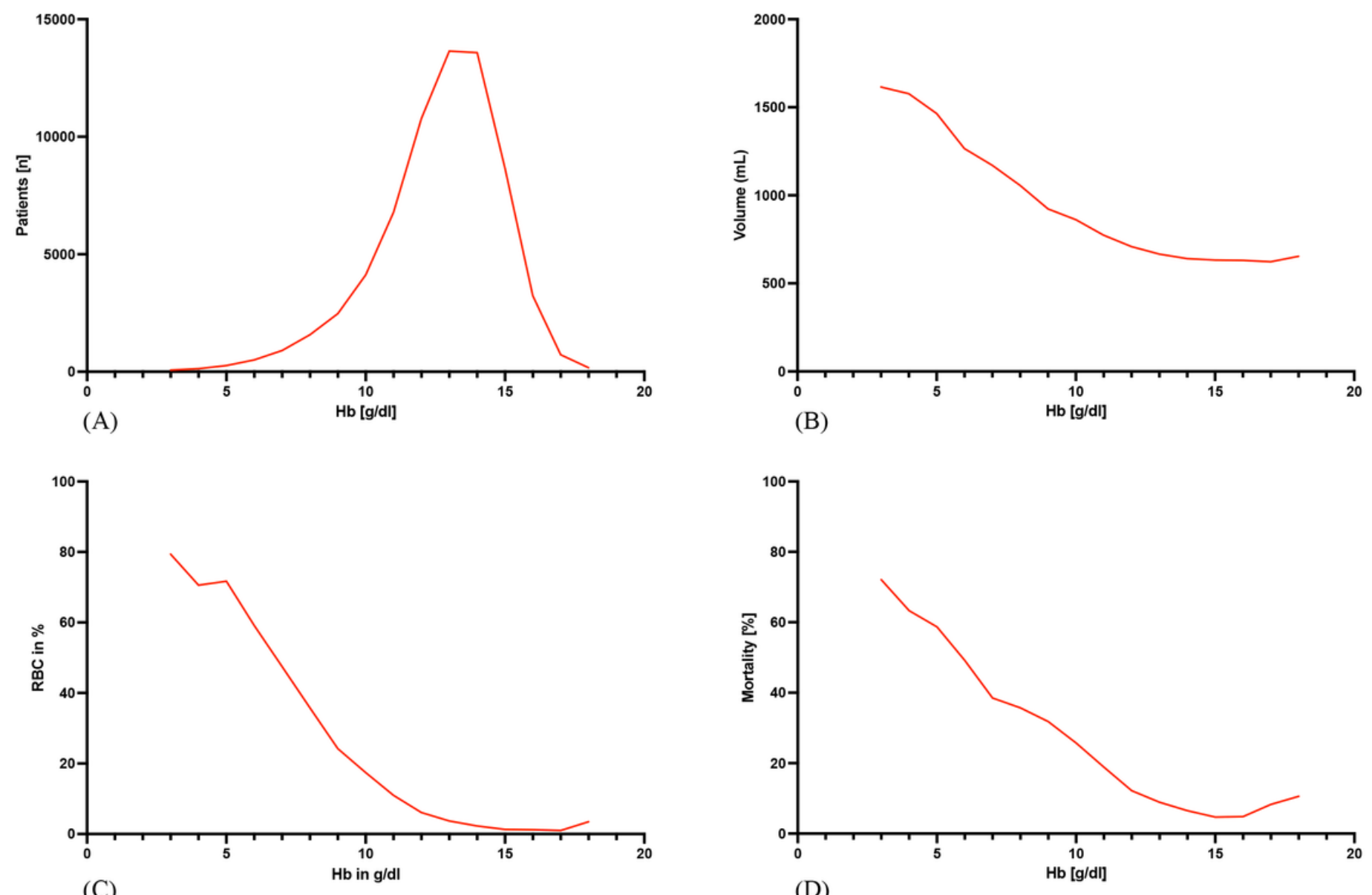

(D)

\section{Figure 2}

Correlation of haemoglobin concentration and mean pre-hospital volume, blood transfusion rate and mortality. (A) Distribution of $\mathrm{Hb}$ values at admission are illustrated. Mean $\mathrm{Hb}$ value at admission was $12.66 \mathrm{~g} / \mathrm{dl}$. Hb values $\leq 3 \mathrm{~g} / \mathrm{dl}$ and $\geq 18 \mathrm{~g} / \mathrm{dl}$ were pooled for means of comparison. (B) Distribution of pre-hospital volume therapy is illustrated. Pre-hospital volume therapy ranges from $500 \mathrm{~mL}$ to $1,500 \mathrm{~mL}$. (C) Distribution of RBC transfusion in ER rate related to $\mathrm{Hb}$ values are illustrated. Rate of RBC transfusion increases exponentially with decreasing $\mathrm{Hb}$ values. (D) Mortality rate associated with $\mathrm{Hb}$ value is illustrated. The mortality rate rises exponentially with decreasing $\mathrm{Hb}$ values. $\mathrm{Hb}=$ haemoglobin, $\mathrm{RBC}=$ red blood cell 


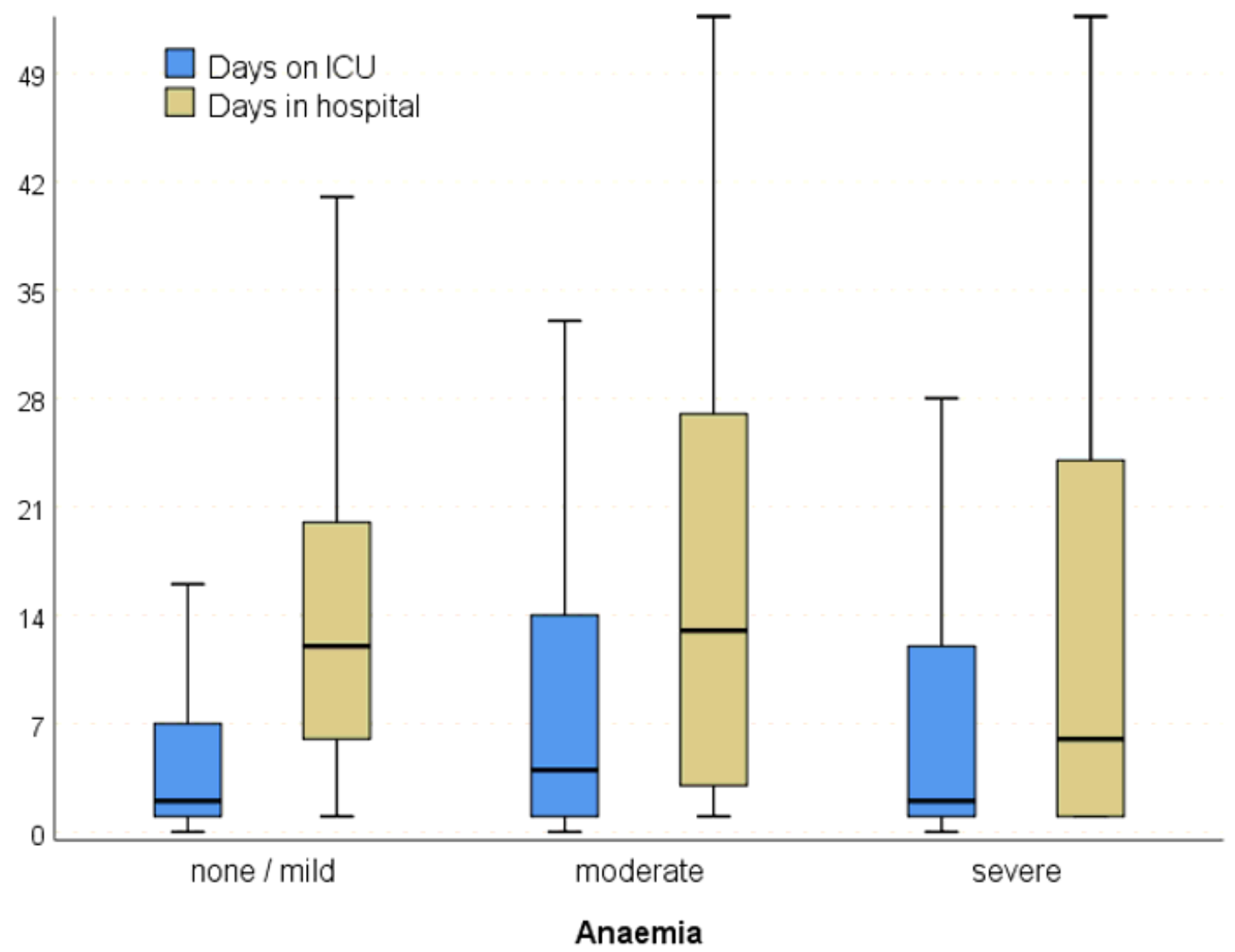

Figure 3

Length of Hospital Stay for surviving patients. Length of Hospital Stay was associated with severity of anaemia 